\title{
Trastuzumab emtansine in the treatment of HER2-positive metastatic breast cancer in Japanese patients
}

This article was published in the following Dove Press journal:

Breast Cancer: Targets and Therapy

15 April 2014

Number of times this article has been viewed

\section{Masataka Sawaki}

Department of Breast Oncology, Aichi Cancer Center Hospital, Nagoya, Japan
Correspondence: Masataka Sawaki Department of Breast Oncology,Aichi Cancer Center Hospital, I-I Kanokoden, Chikusa-ku,

Nagoya 464-868I, Japan

$\mathrm{Tel}+8 \mathrm{I} 5276261 \mathrm{II}$

Fax +8I 527642963

Emailm-sawaki@aichi-cc.jp

\begin{abstract}
Anti-HER2 agents, such as trastuzumab, lapatinib, trastuzumab emtansine (T-DM1), and pertuzumab, are standard agents in the treatment of breast cancer overexpressing the human epidermal growth factor receptor 2 (HER2). Trastuzumab is the first approved HER2-targeted agent. Subsequent developments include agents with different mechanisms. In this paper, we review the results of clinical trials of T-DM1, a new anti-HER2 agent, with a focus on Japanese patients with breast cancer. On the basis of results from a Phase I study (JO22591), the maximum tolerated dose was determined to be $3.6 \mathrm{mg} / \mathrm{kg}$ every 3 weeks for both Japanese and western patients. In a Phase II study (JO22997), the overall response rate was 38.4\% (90\% confidence interval 28.8-48.6). T-DM1 was well tolerated in Japanese patients; however, the incidence of grade 3 or 4 thrombocytopenia was higher than that observed in earlier western studies, but was not associated with clinically important symptoms. Pharmacokinetic parameters for T-DM1 and its metabolites were consistent with those reported previously from a Phase I or II study in non-Japanese patients, and the data obtained showed no suggestion of ethnic differences. Several Phase III studies of T-DM1 are ongoing throughout the world, including in Japanese patients with breast cancer.
\end{abstract}

Keywords: breast cancer, HER2/neu, trastuzumab emtansine, anti-HER2 therapy

\section{Introduction}

The human epidermal growth factor receptor 2 (HER2) protein is a unique and useful target for antibody therapy against breast cancers overexpressing the HER2/neu gene. HER2 is overexpressed in $15 \%-25 \%$ of human breast cancers ${ }^{1-3}$ and is correlated with a poor prognosis in women with both node-positive and node-negative disease. ${ }^{46}$ Overexpression of HER2 has also been associated with potentially more aggressive tumors. Trastuzumab, a humanized monoclonal antibody, was the first agent approved for antiHER2-targeted treatment. Subsequent developments have included agents with different mechanisms, such as lapatinib, trastuzumab emtansine (T-DM1), and pertuzumab.

T-DM1 is an antibody-drug conjugate incorporating the HER2-targeted antitumor properties of trastuzumab with the cytotoxic activity of the microtubule-inhibitory agent, DM1 (a derivative of maytansine); the antibody and cytotoxic agent are conjugated via a stable linker. In the pivotal T-DM1 study (A Randomized, Multicenter, Phase III Open-label Study of the Efficacy and Safety of Trastuzumab Emtansine vs. Capecitabine + Lapatinib in Patients With HER2-positive Locally Advanced or Metastatic Breast Cancer Who Have Received Prior Trastuzumab-based Therapy [EMILIA] $){ }^{7}$ T-DM1 significantly prolonged progression-free survival and overall survival, with less toxicity than lapatinib plus capecitabine in HER2-positive patients with 
advanced breast cancer previously treated by trastuzumab and a taxane. On the basis of that trial, the US Food and Drug Administration approved marketing of T-DM1 in February 2013. T-DM1 has not yet been approved (as of January 2014) in Japan, but approval is expected in 2014. This review describes the results obtained with T-DM1, with particular reference to Japanese patients with breast cancer.

\section{Phase I study in Japanese patients}

A Phase I, multicenter, single-arm, dose-escalation study (JO22591) was performed in Japanese patients with HER2positive metastatic breast cancer who had received prior anticancer therapy. ${ }^{8}$ Ten patients were recruited, divided into three groups, and started at the following T-DM1 doses: $1.8 \mathrm{mg} /$ $\mathrm{kg}(\mathrm{n}=1) ; 2.4 \mathrm{mg} / \mathrm{kg}(\mathrm{n}=4)$; and $3.6 \mathrm{mg} / \mathrm{kg}(\mathrm{n}=5)$. Each dose was given at 3-weekly intervals. Maximum tolerated dose was defined as the dose at which the estimated probability of dose-limiting toxicity is closest to $25 \%$, which is the target probability of dose-limiting toxicity using the continual reassessment method. One patient in the $2.4 \mathrm{mg} / \mathrm{kg}$ group experienced a dose-limiting toxicity (a grade 3 increase in aspartate aminotransferase and alanine aminotransferase). No other adverse events indicating a dose-limiting toxicity were observed in any of the other patients. The most frequently reported adverse events were nausea, fatigue, arthralgia, and pyrexia. The main changes in laboratory test values recorded were a decrease in platelet count and increases in aspartate aminotransferase and alanine aminotransferase levels. Most of the adverse events were mild and manageable, although two serious adverse events were observed, ie, cholelithiasis (grade 3 ) in the $2.4 \mathrm{mg} / \mathrm{kg}$ group and gastric ulcer hemorrhage (grade 2) in the $3.6 \mathrm{mg} / \mathrm{kg}$ group. In total, one patient treated with T-DM1 $2.4 \mathrm{mg} / \mathrm{kg}$ developed a dose-limiting toxicity. No other dose-limiting toxicities were observed for the three doses tested. Thus, as a result of this Phase I study in Japanese patients with breast cancer, the maximum tolerated dose was determined to be $3.6 \mathrm{mg} / \mathrm{kg}$ every 3 weeks.

T-DM1 showed linear pharmacokinetics, with no significant accumulation across the dose levels tested. There were no marked differences between this study and the two western studies (TDM3569 $\mathrm{g}^{9}$ and TDM4258g $\mathrm{g}^{10}$ ) in any of the pharmacokinetic parameters for T-DM1, DM1; a derivative of maytansine, or total trastuzumab following administration of T-DM1. Moreover, there was no suggestion in the data of any ethnic differences between Japanese and western patients.

\section{Phase II study in Japanese patients}

After completing the Phase I study, ${ }^{8}$ which determined a maximum tolerated dose for T-DM1 of $3.6 \mathrm{mg} / \mathrm{kg}$ every 3 weeks, a multicenter, single-arm, Phase II study was started in Japanese patients with HER2-positive metastatic breast cancer who had received prior trastuzumab and at least one line of chemotherapy (JO22997). ${ }^{11}$ T-DM1 was infused as a single agent at a dose of $3.6 \mathrm{mg} / \mathrm{kg}$ every 3 weeks to patients with HER2-positive metastatic breast cancer. The primary endpoint was the objective response rate based on assessment by the independent review committee. Seventy-six patients were enrolled, of whom 73 received at least one dose of T-DM1 and a median of three (range 1-8) prior chemotherapy regimens for metastatic breast cancer, including lapatinib in $43(58.9 \%)$ patients. The median duration of treatment with T-DM1 was $23.1(0.1-63.3)$ weeks. The objective response rate was $38.4 \%$ (90\% confidence interval [CI] 28.8-48.6). The clinical benefit rate was 45.2\% (95\% CI 33.5-57.3) and median progression-free survival was 5.6 months $(95 \%$ CI 4.6-8.2). The most frequently observed grade $\geq 3$ adverse event was thrombocytopenia (22\%). Seventy patients (96\%) experienced an adverse event of any grade, 15 patients $(21 \%)$ experienced a serious adverse event and 41 patients $(56 \%)$ experienced a grade $\geq 3$ adverse event. The incidence of grade 3 or 4 thrombocytopenia was higher than that previously reported in other studies, ${ }^{7,10,12}$ although no patient required a platelet transfusion. Thrombocytopenia is the most common adverse event and key dose-limiting toxicity associated with T-DM1, 9,13,14 and is thought to be due to antimitotic effects on megakaryocyte precursors. However, the rapid onset and recovery of T-DM1-associated thrombocytopenia, even after repeated dosing, suggests that other tubulin-dependent

Table I Pharmacokinetic parameters of T-DMI at $3.6 \mathrm{mg} / \mathrm{kg}$

\begin{tabular}{|c|c|c|c|c|}
\hline \multirow[t]{2}{*}{ Trial name } & \multicolumn{4}{|l|}{ Mean (SD) } \\
\hline & $\mathrm{AUC}_{\text {inf }}($ day $\mu \mathrm{g} / \mathrm{mL})$ & $t_{1 / 2}$ (day) & $\mathrm{V}_{\mathrm{ss}}(\mathrm{mL} / \mathrm{kg})$ & Clearance (mL/day/kg) \\
\hline JO2259| ${ }^{8}(n=5)$ & $346(4 I . I)$ & $3.74(1.15)$ & $59.1(6.62)$ & $10.6(1.26)$ \\
\hline JO229974 (n=3I) & $365(68)$ & $3.62(0.78)$ & $54.9(13.9)$ & $10.3(2.30)$ \\
\hline TDM4258g $\mathrm{g}^{10,15}(\mathrm{n}=10 \mathrm{I})$ & 457 (I29) & $3.52(0.7 I)$ & $28.4(12.9)$ & $8.51(2.69)$ \\
\hline TDM4374g ${ }^{15}(n=105)$ & $486(14 I)$ & $3.96(0.96)$ & $31.2(10.9)$ & $8.04(2.97)$ \\
\hline
\end{tabular}

Abbreviations: $\mathrm{AUC}_{\text {inf }}$ area under the concentration-time curve from time 0 extrapolated to infinity; $t_{1 / 2}$, half-life; $\mathrm{V}_{\mathrm{s}}$, volume of distribution at steady state; $\mathrm{SD}$, standard deviation; T-DMI, trastuzumab emtansine. 
Table 2 Efficacy of T-DMI as monotherapy

\begin{tabular}{|c|c|c|c|c|c|c|}
\hline Trial name & Phase & $\mathbf{n}$ & Treatment setting & ORR (\%) & PFS (months) & Reference \\
\hline JO22997 & II & 73 & Second-line & $38.4(90 \% \mathrm{Cl} 28.8-48.6)$ & $5.6(95 \% \mathrm{Cl} 4.6-8.2)$ & Masuda et al $^{\prime \prime}$ \\
\hline TDM4258g & ॥ & 112 & Second-line & $25.9(95 \% \mathrm{Cl} 18.4-34.4)$ & $4.6(95 \% \mathrm{Cl} 3.9-8.6)$ & Burris et $\mathrm{al}^{10}$ \\
\hline TDM4374g & II & 110 & Second-line & $34.5(95 \% \mathrm{Cl} 26.1-43.9)$ & $6.9(95 \% \mathrm{Cl} 4.2-8.4)$ & Krop et al ${ }^{12}$ \\
\hline TDM4450g & II (randomized) & 67 & First-line & $64.2(95 \% \mathrm{Cl} 5 \mathrm{I} .8-74.8)$ & 14.2 & Hurvitz et $\mathrm{a}^{23}$ \\
\hline EMILIA & III & 495 & Second-line & $43.6(95 \% \mathrm{Cl} 38.6-48.6)$ & 9.4 & Verma et $\mathrm{al}^{7}$ \\
\hline
\end{tabular}

Abbreviations: $\mathrm{Cl}$, confidence interval; PFS, progression-free survival; ORR, objective response rate; T-DMI, trastuzumab emtansine; EMILA, A Randomized, Multicenter, Phase III Open-label Study of the Efficacy and Safety of Trastuzumab Emtansine vs. Capecitabine + Lapatinib in Patients With HER2-positive Locally Advanced or Metastatic Breast Cancer Who Have Received Prior Trastuzumab-based Therapy.

mechanisms, such as release of proplatelets from mature megakaryocytes, may be important. ${ }^{9}$

The pharmacokinetic parameters of T-DM1 identified in the Phase I and II studies from Japan are summarized in Table 1. There were no marked differences in any of the pharmacokinetic parameters for T-DM1, DM1, or total trastuzumab following administration of T-DM1 between the four studies, ie, the Japanese Phase I study (JO22591; n=5), the Japanese Phase II study (JO22997; $\mathrm{n}=31),{ }^{11} \mathrm{TDM} 4258 \mathrm{~g}$ $(\mathrm{n}=101),{ }^{15}$ and TDM4374g $(\mathrm{n}=105) .{ }^{15}$

In summarizing the Phase II study, the objective response rate (the primary endpoint established by the independent review committee) was $38.4 \%$, and T-DM1 was well tolerated. Table 2 gives a comparison of the efficacy of T-DM1 in Japanese patients versus western patients. A good response was seen in both patient populations. These results support the use of T-DM1 in the treatment of Japanese patients with advanced HER2-positive breast cancer previously treated with chemotherapy and trastuzumab.

\section{Phase Ib study in Japanese patients}

A multicenter, single-arm, Phase Ib study (JO22992) using a combination of T-DM1 and pertuzumab was performed in
Japanese patients with HER2-positive metastatic breast cancer who had received prior treatment with trastuzumab and chemotherapy. ${ }^{16}$ Six patients received T-DM1 $3.6 \mathrm{mg} / \mathrm{kg}$ with pertuzumab (a $840 \mathrm{mg}$ loading dose, then a $420 \mathrm{mg}$ maintenance dose) given every 3 weeks. The median duration of treatment was eleven (range 1-32) cycles. Grade $\geq 3$ adverse events included one case each of increased aspartate aminotransferase, decreased left ventricular ejection fraction, and neutropenia. A grade 3 decrease in left ventricular ejection fraction during cycle 1 led to discontinuation, but resolved within 30 days. Two serious adverse events (hemorrhagic gastric ulcer and epistaxis) occurred in one patient. The pharmacokinetic parameters of both drugs were similar to those seen in the single-agent trials. The objective response rate was $50 \%$. In conclusion, the combination of T-DM1 and pertuzumab showed encouraging results regarding tolerability in Japanese patients with HER2-positive metastatic breast cancer.

\section{Phase III study}

The Phase III studies of T-DM1 are summarized in Table 3. EMILIA, the global Phase III study of T-DM1, showed novel efficacy and less toxicity than lapatinib and capecitabine as

Table 3 Phase III studies of T-DMI

\begin{tabular}{|c|c|c|c|c|}
\hline Trial name & Standard arm & Experimental arm & Treatment setting & $\begin{array}{l}\text { Target number } \\
\text { (total) }\end{array}$ \\
\hline $\begin{array}{l}\text { MARIANNE } 18, * \\
(\text { NCT0II } 20184)\end{array}$ & $\begin{array}{l}\text { Trastuzumab + taxane } \\
\text { (docetaxel or paclitaxel) }\end{array}$ & $\begin{array}{l}\text { T-DMI + pertuzumab } \\
\text { T-DMI + pertuzumab placebo }\end{array}$ & MBC; first-line & 1,095 \\
\hline $\begin{array}{l}\text { TH3RESA }{ }^{20} \\
\text { (NCT0I4I9I97) }\end{array}$ & $\begin{array}{l}\text { Treatment of physician's } \\
\text { choice }\end{array}$ & T-DMI & MBC; third-line & 604 \\
\hline $\begin{array}{l}\text { KAITLIN }^{21, *} \\
(\text { NCT0I96647I) }\end{array}$ & $\begin{array}{l}\text { Trastuzumab + pertuzumab } \\
+ \text { taxane }\end{array}$ & T-DMI + pertuzumab & $\begin{array}{l}\text { Adjuvant therapy; following } \\
\text { anthracyclines }\end{array}$ & 2,500 \\
\hline $\begin{array}{l}\text { KATHERINE }^{23} \\
\text { (NCTOI772472) }\end{array}$ & Trastuzumab & T-DMI & $\begin{array}{l}\text { Adjuvant therapy; following } \\
\text { preoperative therapy }\end{array}$ & $\mathrm{I}, 484$ \\
\hline
\end{tabular}

Note: *Japanese breast cancer patients participating.

Abbreviations: MBC, metastatic breast cancer; T-DMI, trastuzumab emtansine; MARIANNE, A Study of Trastuzumab-DMI Plus Pertuzumab Versus Trastuzumab [Herceptin] Plus a Taxane in Patients With Metastatic Breast Cancer; TH3RESA, A Study of Trastuzumab Emtansine in Comparison With Treatment of Physician's Choice in Patients With HER2-Positive Breast Cancer Who Have Received at Least Two Prior Regimens of HER2-Directed Therapy; KAITLIN, A Study of Kadcyla (Trastuzumab Emtansine) Plus Perjeta (Pertuzumab) Following Anthracyclines in Comparison With Herceptin (Trastuzumab) Plus Perjeta and a Taxane Following Anthracyclines as Adjuvant Therapy in Patients With Operable HER2-positive Primary Breast Cancer; KATHERINE, A Study of Trastuzumab Emtansine Versus Trastuzumab as Adjuvant Therapy in Patients With HER2-Positive Breast Cancer Who Have Residual Tumor in the Breast or Axillary Lymph Nodes Following Preoperative Therapy. 
a second-line treatment for HER2-positive metastatic breast cancer. ${ }^{7}$ In the first-line and third-line treatment settings for HER2-positive metastatic breast cancer, the efficacy of T-DM1 when compared with other standard therapies has not been clarified. At present, combination therapy of taxane, trastuzumab and pertuzumab used as standard first-line anti-HER2 therapy. ${ }^{17}$ The Study of Trastuzumab-DM1 Plus Pertuzumab Versus Trastuzumab [Herceptin] Plus a Taxane in Patients With Metastatic Breast Cancer (MARIANNE) trial $^{18}$ will show whether or not T-DM1 with or without pertuzumab is superior to a taxane with trastuzumab as first-line therapy, although the Phase III, Randomized, Double-blind, Placebocontrolled Clinical Trial to Evaluate the Efficacy and Safety of Pertuzumab + Trastuzumab + Docetaxel vs. Placebo + Trastuzumab + Docetaxel in Previously Untreated HER2positive Metastatic Breast Cancer (CLEOPATRA) trial ${ }^{19}$ indicates notable efficacy of pertuzumab plus trastuzumab plus docetaxel in this setting. ${ }^{17}$ This trial included Japanese breast cancer patients.

The Study of Trastuzumab Emtansine in Comparison With Treatment of Physician's Choice in Patients With HER2-Positive Breast Cancer Who Have Received at Least Two Prior Regimens of HER2-Directed Therapy (TH3RESA) trial $^{20}$ is comparing T-DM1 with physician's choice of treatment as a third line for HER2-positive metastatic breast cancer, although Japanese breast cancer patients are not included. This trial has completed accrual and results are awaited.

In the Study of Kadcyla (Trastuzumab Emtansine) Plus Perjeta (Pertuzumab) Following Anthracyclines in Comparison With Herceptin (Trastuzumab) Plus Perjeta and a Taxane Following Anthracyclines as Adjuvant Therapy in Patients With Operable HER2-positive Primary Breast Cancer (KAITLIN) trial, ${ }^{21}$ T-DM1 plus pertuzumab is being compared with trastuzumab plus taxane plus pertuzumab followed by anthracycline as adjuvant therapy for HER2-positive breast cancer. Japanese breast cancer patients will participate in KAITLIN. In this trial, trastuzumab with taxane plus pertuzumab is the standard treatment arm, but whether or not addition of pertuzumab is superior to trastuzumab plus a taxane has not yet been clarified, and this is expected to be answered by the Randomized Multicenter, Double-blind, Placebo-controlled Comparison of Chemotherapy Plus Trastuzumab Plus Placebo Versus Chemotherapy Plus Trastuzumab Plus Pertuzumab as Adjuvant Therapy in Patients With Operable HER2-positive Primary Breast Cancer (APHINITY) trial. ${ }^{22}$

\section{Disclosure}

The author reports no conflicts of interest in this work.

\section{References}

1. Slamon DJ, Clark GM, Wong SG, Levin WJ, Ullrich A, McGuire WL. Human breast cancer: correlation of relapse and survival with amplification of the HER-2/neu oncogene. Science. 1987;235:177-182.

2. Slamon DJ, Godolphin W, Jones LA, et al. Studies of the HER-2/ neu proto-oncogene in human breast and ovarian cancer. Science. 1989;244:707-712.

3. Gusterson BA, Gelber RD, Goldhirsch A, et al. Prognostic importance of c-erbB-2 expression in breast cancer. International (Ludwig) Breast Cancer Study Group. J Clin Oncol. 1992;10:1049-1056.

4. Seshadri R, Firgaira FA, Horsfall DJ, McCaul K, Setlur V, Kitchen P. Clinical significance of HER-2/neu oncogene amplification in primary breast cancer. The South Australian Breast Cancer Study Group. J Clin Oncol. 1993;11:1936-1942.

5. Ravdin PM, Chamness GC. The c-erbB-2 proto-oncogene as a prognostic and predictive marker in breast cancer: a paradigm for the development of other macromolecular markers - a review. Gene. 1995;159: 19-27.

6. Press MF, Bernstein L, Thomas PA, et al. HER-2/neu gene amplification characterized by fluorescence in situ hybridization: poor prognosis in node-negative breast carcinomas. J Clin Oncol. 1997;15: 2894-2904.

7. Verma S, Miles D, Gianni L, et al. Trastuzumab emtansine for HER2-positive advanced breast cancer. $N$ Engl J Med. 2012;367: 1783-1791.

8. Aogi K, Ando M, Iwata H, Hara F, Matsubara M, Fujiwara Y. Phase I study of single agent trastuzumab emtansine in japanese patients with human epidermal growth factor receptor 2 (HER2)-positive metastatic breast cancer (JO22591). Cancer Res. 2011;71(Suppl 24):Abstr nr P1-12-19.

9. Krop IE, Beeram M, Modi S, et al. Phase I study of trastuzumab-DM1, an HER2 antibody-drug conjugate, given every 3 weeks to patients with HER2-positive metastatic breast cancer. J Clin Oncol. 2010;28: 2698-2704.

10. Burris HA 3rd, Rugo HS, Vukelja SJ, et al. Phase II study of the antibody drug conjugate trastuzumab-DM1 for the treatment of human epidermal growth factor receptor 2 (HER2)-positive breast cancer after prior HER2-directed therapy. J Clin Oncol. 2011;29:398-405.

11. Masuda N, Ito Y, Takao S, et al. A multicenter Phase 2 study (JO22997) evaluating the efficacy and safety of trastuzumab emtansine in japanese patients with heavily pretreated HER2-positive metastatic breast cancer. Cancer Res. 2012;72 (Suppl 24):Abstr nr P5-18-16.

12. Krop IE, LoRusso P, Miller KD, et al. A Phase II study of trastuzumab emtansine in patients with human epidermal growth factor receptor 2-positive metastatic breast cancer who were previously treated with trastuzumab, lapatinib, an anthracycline, a taxane, and capecitabine. J Clin Oncol. 2012;30:3234-3241.

13. Beeram M, Krop IE, Burris HA, et al. A Phase 1 study of weekly dosing of trastuzumab emtansine (T-DM1) in patients with advanced human epidermal growth factor 2-positive breast cancer. Cancer. 2012;118: 5733-5740.

14. Bender BC, Schaedeli-Stark F, Koch R, et al. A population pharmacokinetic/pharmacodynamic model of thrombocytopenia characterizing the effect of trastuzumab emtansine (T-DM1) on platelet counts in patients with HER2-positive metastatic breast cancer. Cancer Chemother Pharmacol. 2012;70:591-601.

15. Girish S, Gupta M, Wang B, et al. Clinical pharmacology of trastuzumab emtansine (T-DM1): an antibody-drug conjugate in development for the treatment of HER2-positive cancer. Cancer Chemother Pharmacol. 2012;69:1229-1240.

16. Iwata H, Horiguchi J, Sato N, Fujiwara Y. A Phase Ib trial of trastuzumab emtansine in combination with pertuzumab. Japan Society of Clinical Oncology. 2013:Abstr O10-5. Available from: http://jsco.members-web. com/51award_eng/ct_04.php. Accessed February 23, 2014.

17. Baselga J, Cortes J, Kim SB, et al. Pertuzumab plus trastuzumab plus docetaxel for metastatic breast cancer. $N$ Engl J Med. 2012;366: 109-119. 
18. Hoffmann-La Roche. A Study of Trastuzumab Emtansine (T-DM1) Plus Pertuzumab/Pertuzumab Placebo Versus Trastuzumab [Herceptin] Plus a Taxane in Patients With Metastatic Breast Cancer (MARIANNE). Available from: http://clinicaltrials.gov/show/NCT01120184. NLM identifier: NCT01120184. Accessed March 17, 2014.

19. Genentech. A Study to Evaluate Pertuzumab + Trastuzumab + Docetaxel vs. Placebo + Trastuzumab + Docetaxel in Previously Untreated HER2-positive Metastatic Breast Cancer (CLEOPATRA). Available from: http:/clinicaltrials.gov/ct2/show/NCT00567190. NLM identifier: NCT00567190. Accessed January 22, 2014.

20. Hoffmann-La Roche. A Study of Trastuzumab Emtansine in Comparison With Treatment of Physician's Choice in Patients With HER2-Positive Breast Cancer Who Have Received at Least Two Prior Regimens of HER2-Directed Therapy (TH3RESA). Available from: http:// clinicaltrials.gov/show/NCT01419197. NLM identifier: NCT01419197. Accessed January 6, 2014.

21. Hoffmann-La Roche. A Study of Kadcyla (Trastuzumab Emtansine) Plus Perjeta (Pertuzumab) Following Anthracyclines in Comparison With Herceptin (Trastuzumab) Plus Perjeta and a Taxane Following Anthracyclines as Adjuvant Therapy in Patients With Operable HER2positive Primary Breast Cancer. Available from: http://clinicaltrials. gov/show/NCT01966471. NLM identifier: NCT01966471. Accessed March 17, 2014.
22. Hoffmann-La Roche. A Study of Pertuzumab in Addition to Chemotherapy and Herceptin (Trastuzumab) as Adjuvant Therapy in Patients With HER2-Positive Primary Breast Cancer. Available from: http:// clinicaltrials.gov/ct2/show/NCT01358877?term=NCT01358877\& rank=1. NLM identifier: NCT01358877. Accessed March 17, 2014.

23. Hoffmann-La Roche. A Study of Trastuzumab Emtansine Versus Trastuzumab as Adjuvant Therapy in Patients With HER2-Positive Breast Cancer Who Have Residual Tumor in the Breast or Axillary Lymph Nodes Following Preoperative Therapy (KATHERINE). Available from: http:/clinicaltrials.gov/ct2/show/NCT01772472?term=NCT01772472 \&rank=1. NLM identifier: NCT01772472. Accessed March 17, 2014

24. Hurvitz SA, Dirix L, Kocsis J, et al. Phase II randomized study of trastuzumab emtansine versus trastuzumab plus docetaxel in patients with human epidermal growth factor receptor 2-positive metastatic breast cancer. J Clin Oncol. 2013;31:1157-1163.
Breast Cancer: Targets and Therapy

\section{Publish your work in this journal}

Breast Cancer: Targets and Therapy is an international, peerreviewed open access journal focusing on breast cancer research, identification of therapeutic targets and the optimal use of preventative and integrated treatment interventions to achieve improved outcomes, enhanced survival and quality of life for the cancer patient.

\section{Dovepress}

View the full aims and scopes of this journal here. The manuscript management system is completely online and includes a very quick and fair peer-review system, which is all easy to use. Visit http:// www.dovepress.com/testimonials.php to read real quotes from published authors.

Submit your manuscript here: http://www.dovepress.com/breast-cancer---targets-and-therapy-journal 